\title{
Make Me Up
}

Romeo Agata, Trimarchi Domenico, Associazione Voglia di Vivere pro-mielolesi di Catania

Background: The scientific literature shows that improving the physical appearance helps to improve the quality of life. Our project has been started by the "Voglia di Vivere" Association of Catania and it's aimed only for women with spinal cord injuries.

The observational study examined the association between body image and life satisfaction of women with physical disabilities. Through the offer of a make-up course, we want to promote the regaining of one's own femininity and increase the integration with able-bodied people.

Methods: A group of 12 women aged 19 to 55 , suffering from tetra and paraplegia attended a make-up course in a professional school.

The meetings were introduced by the peer counselor. There is always a psychologist, a teacher and three school students as tutors. Makeup artists have taught strategies to improve facial features. The lessons included theoretical insights on basic makeup, brush and color analysis. Women who attended the course have proceeded with the make-up on themselves first and later, with the supervision of the tutors, on other people (a caregiver or a,tutor).

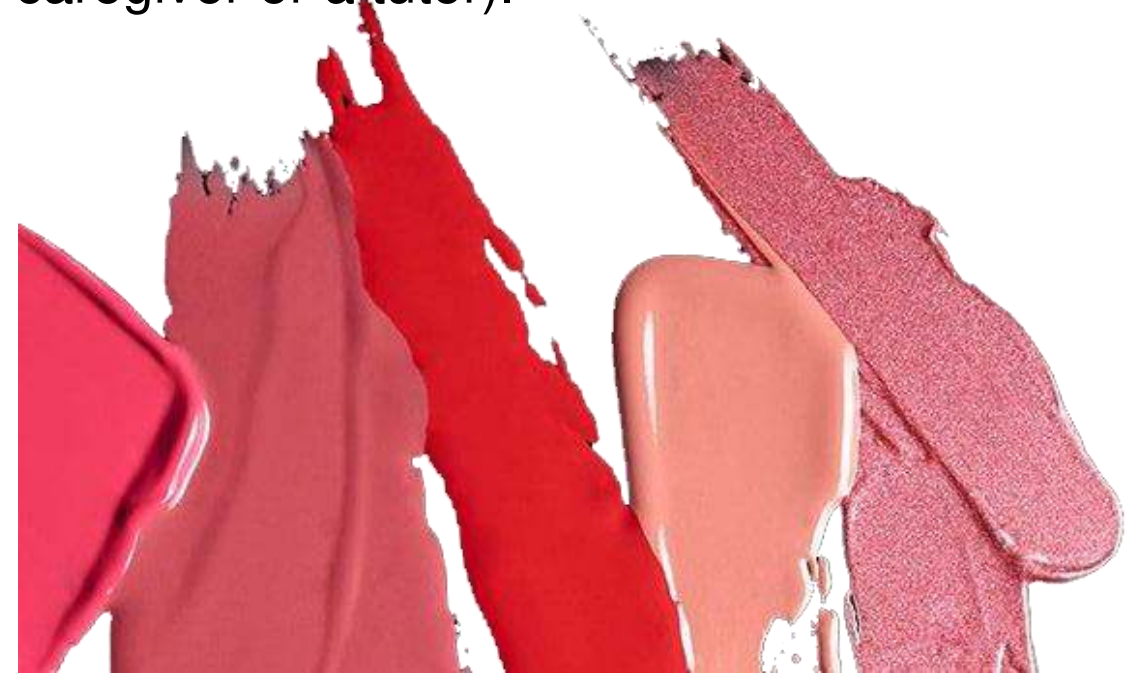

Findings: Keeping the brush in the hands is often difficult, in fact, Enza, did not put on makeup anymore, had abandoned makeup because it made her nervous and other girls did not look anymore in the mirror. Every young woman experimented using the materials that were available to them. Every day they have improved their technique and the use of the materials, finding each one, after various trials, the modality commensurate with their own abilities. Enrolled women have visibly improved selfesteem, well-being and self-confidence even if the body still bears the marks of an experience of rupture and loss.

Discussion: The make-up classes allowed the teachers to understand that, even if a person has experienced a loss, she is able to integrate completely with able-bodied people without feeling different. The construction of a new experience outside the health environment, has allowed the construction of new relationships. The makeup lessons have become places of "taking care" but also of comparison where, the re-discovering has also become a re-discovery of the other in all directions.

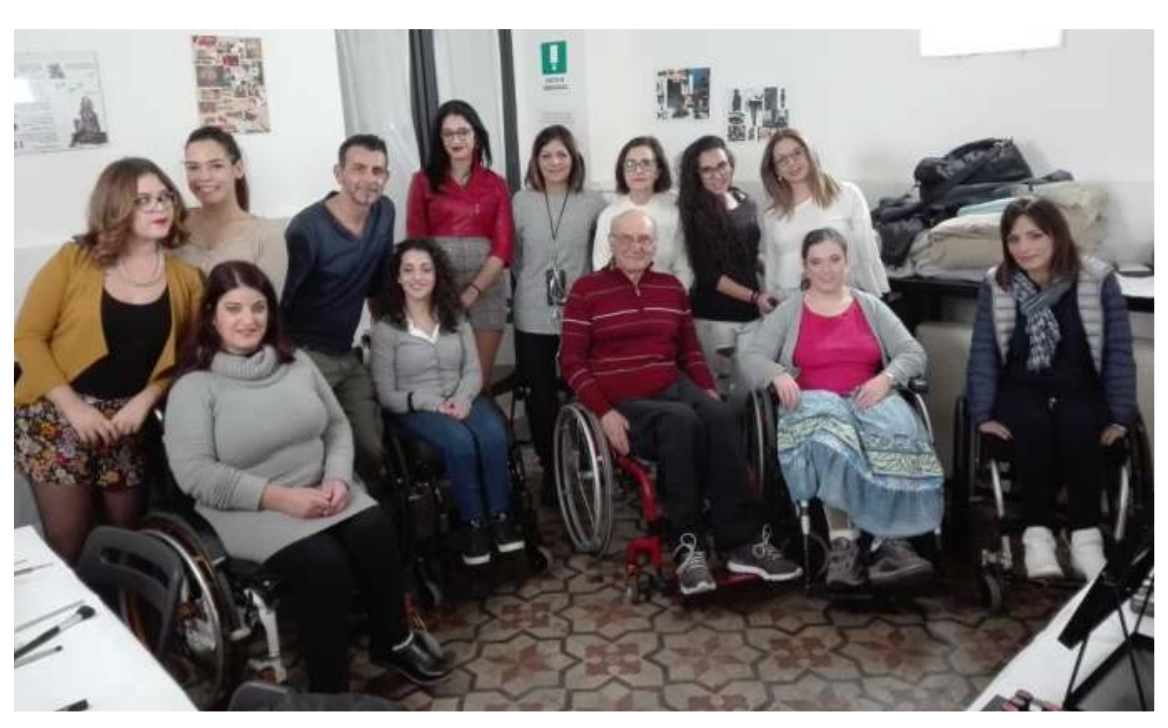

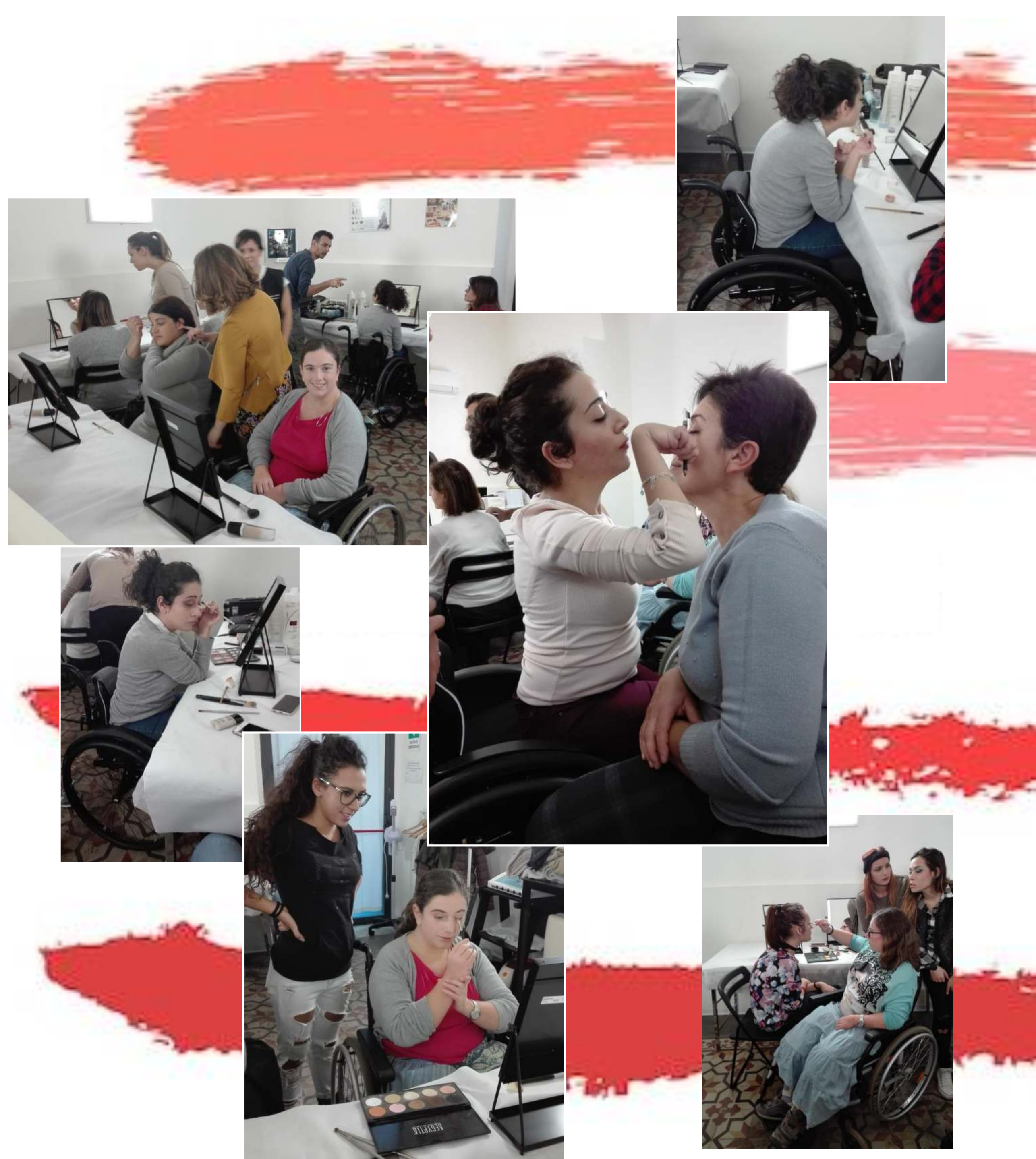

